\title{
Synthetic Studies Towards Combrestatin Analogues via Heck- Matsuda Reaction
}

\author{
André F. P. Biajoli, Francisco de Azambuja and Carlos R. D. Correia* \\ Instituto de Química, UNICAMP, Cx. Postal 6154, CEP 13083-970, Campinas, SP, Brazil \\ troque@iqm.unicamp.br
}

Keywords: palladium, arenediazonium salts, combrestatin

\section{INTRODUCTION}

Combrestatins $^{1}$ (Figure 1) and its analogues are electron rich cis-stilbene compounds possessing remarkable anti-cancer activity. Several studies have demonstrated the tubulin inhibition mode of action of such substances, making those interesting molecules against all types of cancer.

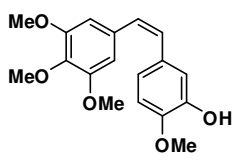

Combrestatin A4
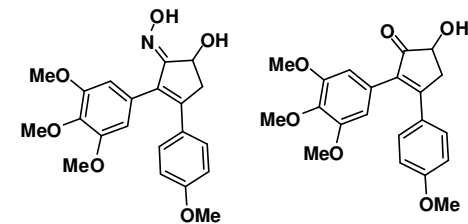

Figure 1. Combrestatins and some analogs

The Heck-Matsuda (HM) reactions ${ }^{2}$ employ arenediazonium salts as arylating agents and present several advantages when compared to traditional protocols (aryl halides or triflates): they are phosphine-free, do not require inert atmosphere, are more economical, and can be carried out at lower temperatures and shorter reaction times. In this work, the HM arylation is evaluated as the key step for the synthesis of combrestatin analogues.

\section{RESULTS AND DISCUSSION}

Dimethyl fumarate was used as substrate for the HM arylation using $\mathrm{Pd}(\mathrm{OAc})_{2}$ as catalyst in $\mathrm{MeOH}$ as solvent with a variety of diazonium salts. The reaction performed best in the absence of a base. Higher yields and selectivity were observed for diazonium salts bearing electron-donating groups (Scheme 1).

$$
\begin{aligned}
& \mathrm{MeO}_{2} \mathrm{C} / \mathrm{CO}_{2} \mathrm{Me}+\underset{\mathrm{R}}{\Delta} \frac{\mathrm{Pd}(\mathrm{OAC})_{2}, \mathrm{MeOH}}{\Delta} \underset{\mathrm{MeO}_{2} \mathrm{C}}{\longrightarrow \mathrm{N}_{2} \mathrm{BF}_{4}} \\
& \mathrm{R}=4-\mathrm{OMe}, 3,4,5-(\mathrm{OMe})_{3}, 4-\mathrm{OH} \text {, } \\
& 3,4-\left(\mathrm{OCH}_{2} \mathrm{O}\right), 2,3-\left(\mathrm{C}_{4} \mathrm{H}_{4}\right) \\
& \mathrm{R}=4-\mathrm{Cl}, 4-\mathrm{Br}, 4-\mathrm{F}, 3-\mathrm{NO}_{2}, 3-\mathrm{CN} \\
& \begin{array}{c}
44-83 \% \\
Z: E=9: 1-10: 0
\end{array} \\
& \begin{array}{c}
16-72 \% \\
=84: 16-98
\end{array}
\end{aligned}
$$

Scheme 1. HM arylation of dimethyl fumarate

The second HM arylation was carried out in the maleic anhydride system, which was constructed by a one-pot hydrolysis/ring-closure protocol as illustrated in Scheme 2.

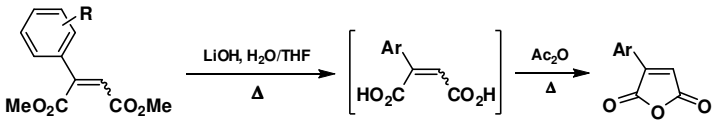

$\mathrm{R}=4-\mathrm{OMe}, 3,4,5-(\mathrm{OMe}) 3,4-\mathrm{Br}, 4-\mathrm{Cl}$ $95 \%$ for all cases Scheme 2. One-pot synthesis of the monoarylated maleic anhydrides

The second HM arylation of the electron-rich monoaryl maleic anhydrides with diazonium salt bearing electron donating groups provided the corresponding adducts in moderate yields (unoptimized, Scheme 3).
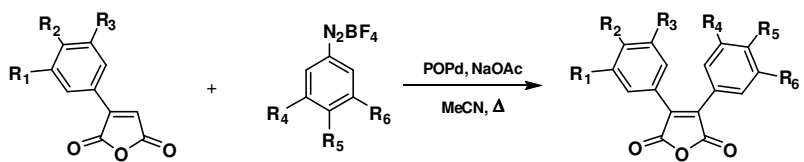

$1 \mathrm{R}_{2}=\mathrm{OMe} \mathrm{R} \mathrm{R}_{1}=\mathrm{R}_{3}=\mathrm{H} \quad \mathrm{R}_{4}=\mathrm{R}_{5}=\mathrm{R}_{6}=\mathrm{OMe}$

$2 R_{1}=R_{2}=R_{3}=O M e \quad R_{5}=O M e R_{4}=R_{6}=H$

$10 \%$

$3 \mathrm{R}_{1}=\mathrm{R}_{2}=\mathrm{R}_{3}=\mathrm{OMe} \quad \mathrm{R}_{4}=\mathrm{OACR}_{5}=\mathrm{OMe} \mathrm{R}_{6}=\mathrm{H}$

$58 \%$

$39 \%(82 \%$ conv. $)$

Scheme 3. HM arylation of maleic anhydride

These diarylated adducts constitutes combrestatins analogues, mainly compound $\mathbf{3}$. Compounds $\mathbf{1}$ and 2 were hydrolyzed and esterified to obtain an acyclic analogue with total stereocontrol (Scheme 4).

$$
\begin{aligned}
& \mathrm{Ar}_{\mathrm{O}} \text { or } 2 \\
& \mathrm{Ar}_{1}=4-\mathrm{OMe} ; \mathrm{Ar}_{2}=3,4,5-\mathrm{OMe}_{3}
\end{aligned}
$$

Scheme 4. Acyclic combrestatin analogue synthesis

\section{CONCLUSION}

New combrestatins analogues were successfully synthesized employing the Heck-Matsuda arylation reaction. Preparation of other analogues and optimization of key steps are under investigation.

\section{ACKNOWLEDGEMENTS}

The authors thank FAPESP and CNPq.

\section{REFERENCES}

${ }^{1}$ Medarde, M.; Maya, A. B. S.; Pérez-Melero, C. J. Enz. Inh. Med. Chem. 2004, 19, 521.

${ }^{2}$ Taylor, J. G.; Moro, A. V.; Correia, C. R. D. Eur. J. Org. Chem. 2011, 1403. 